Steps:
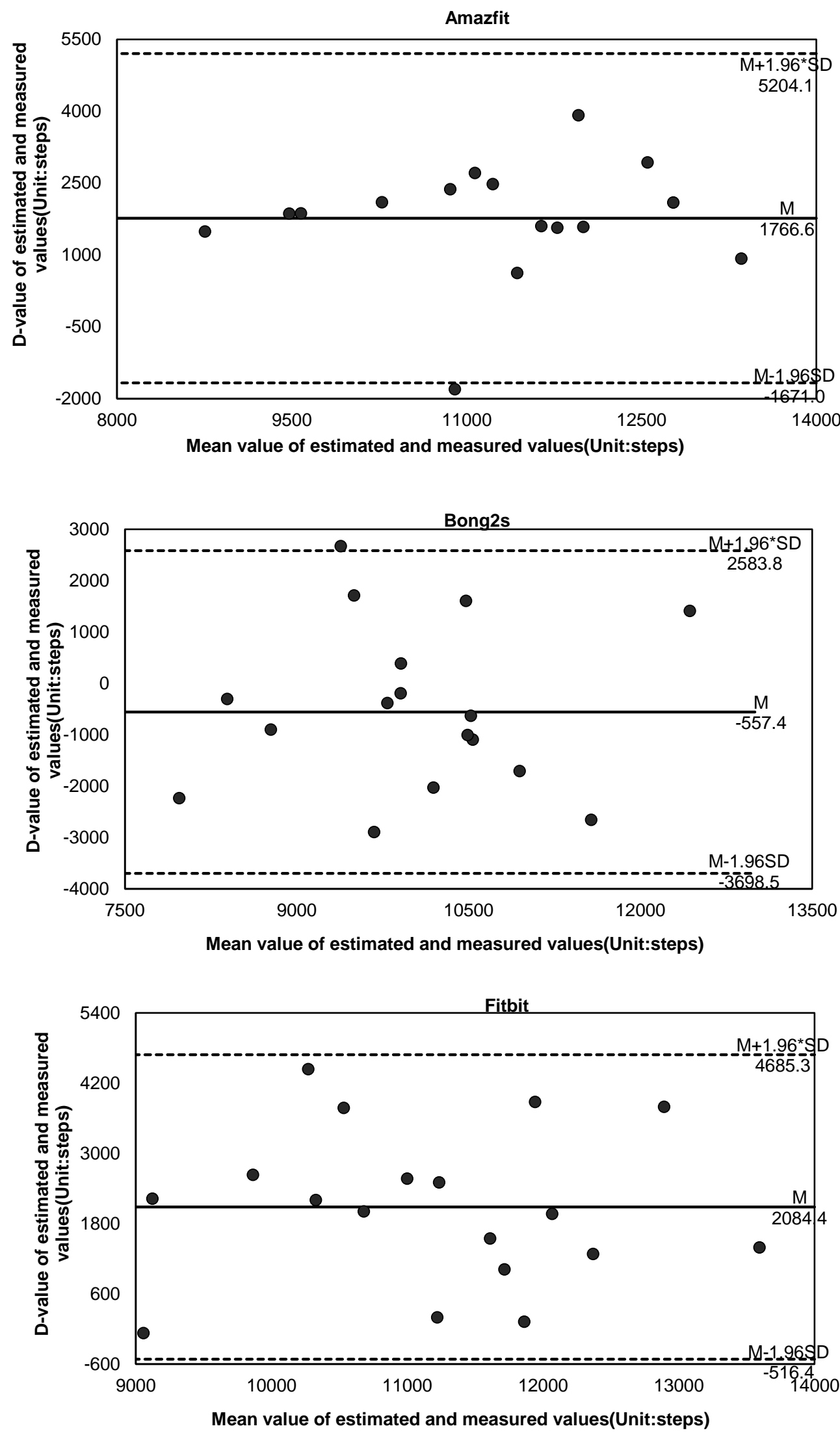

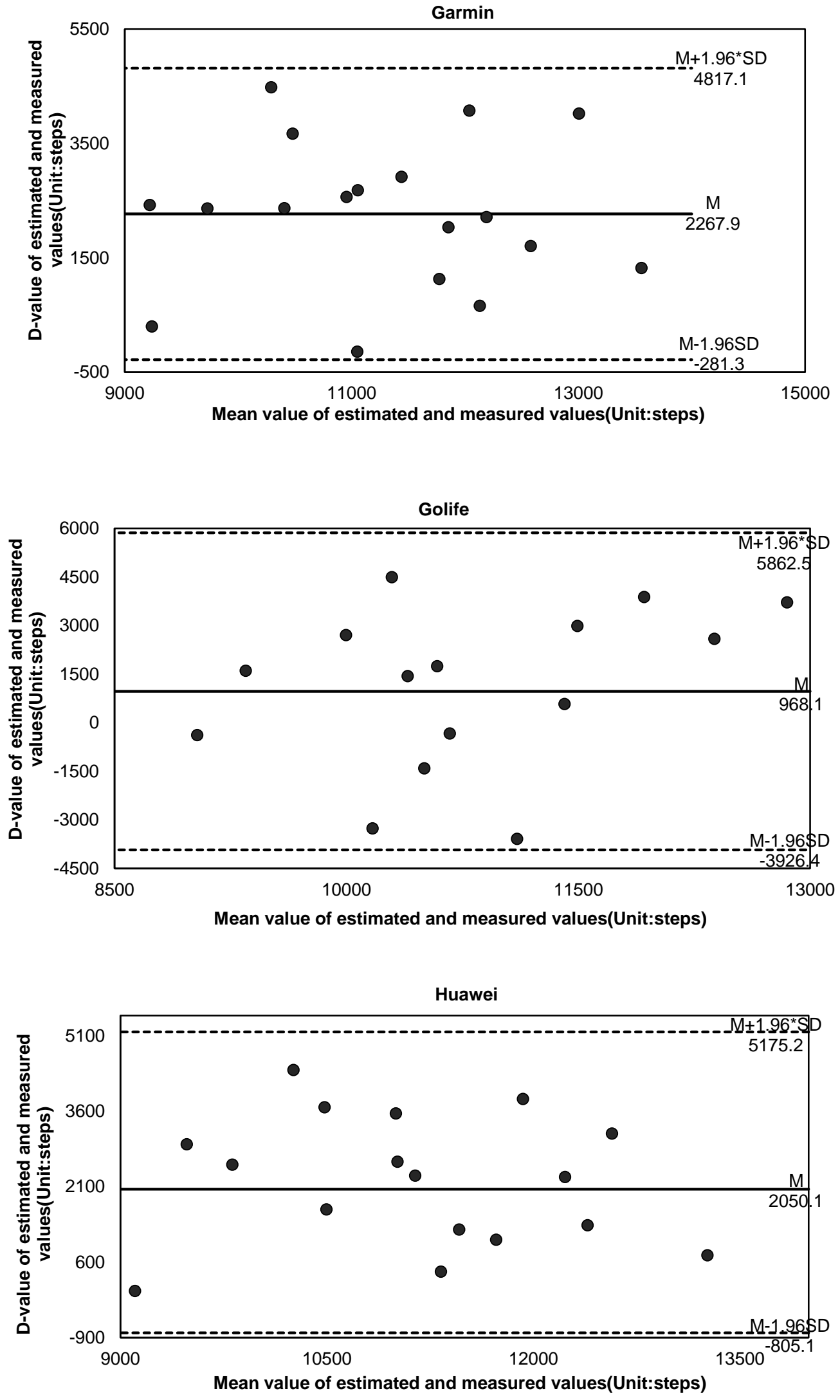


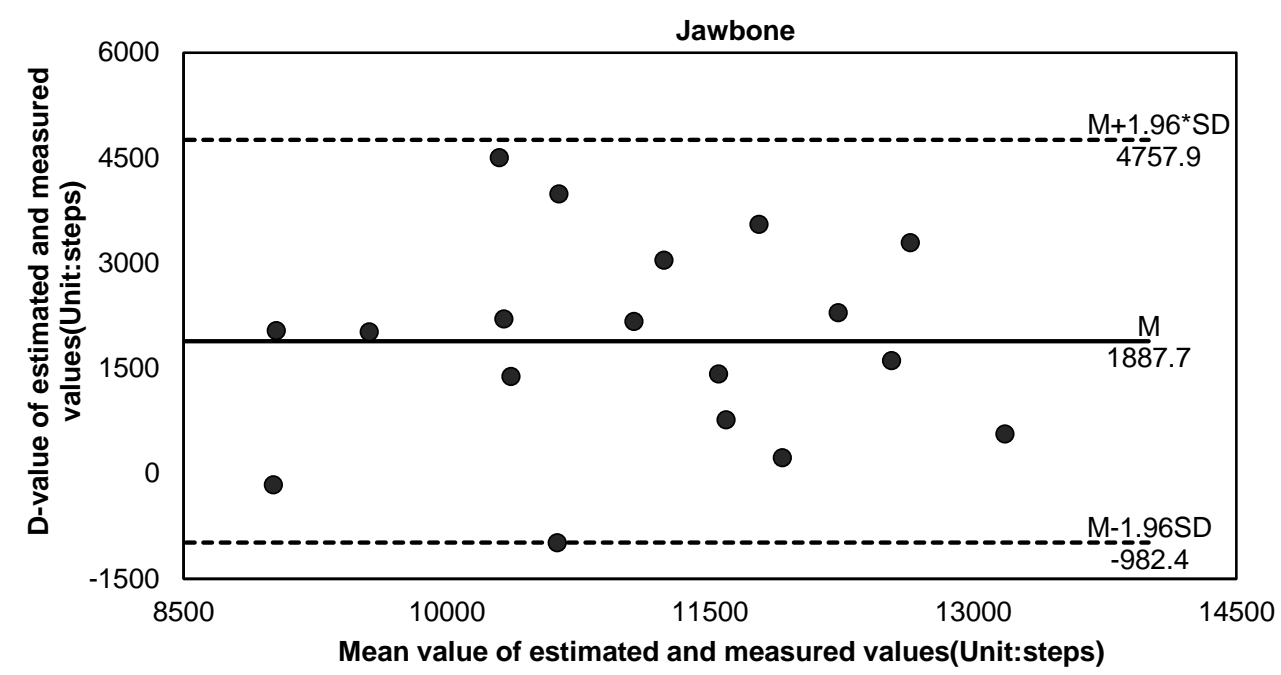

Misfit
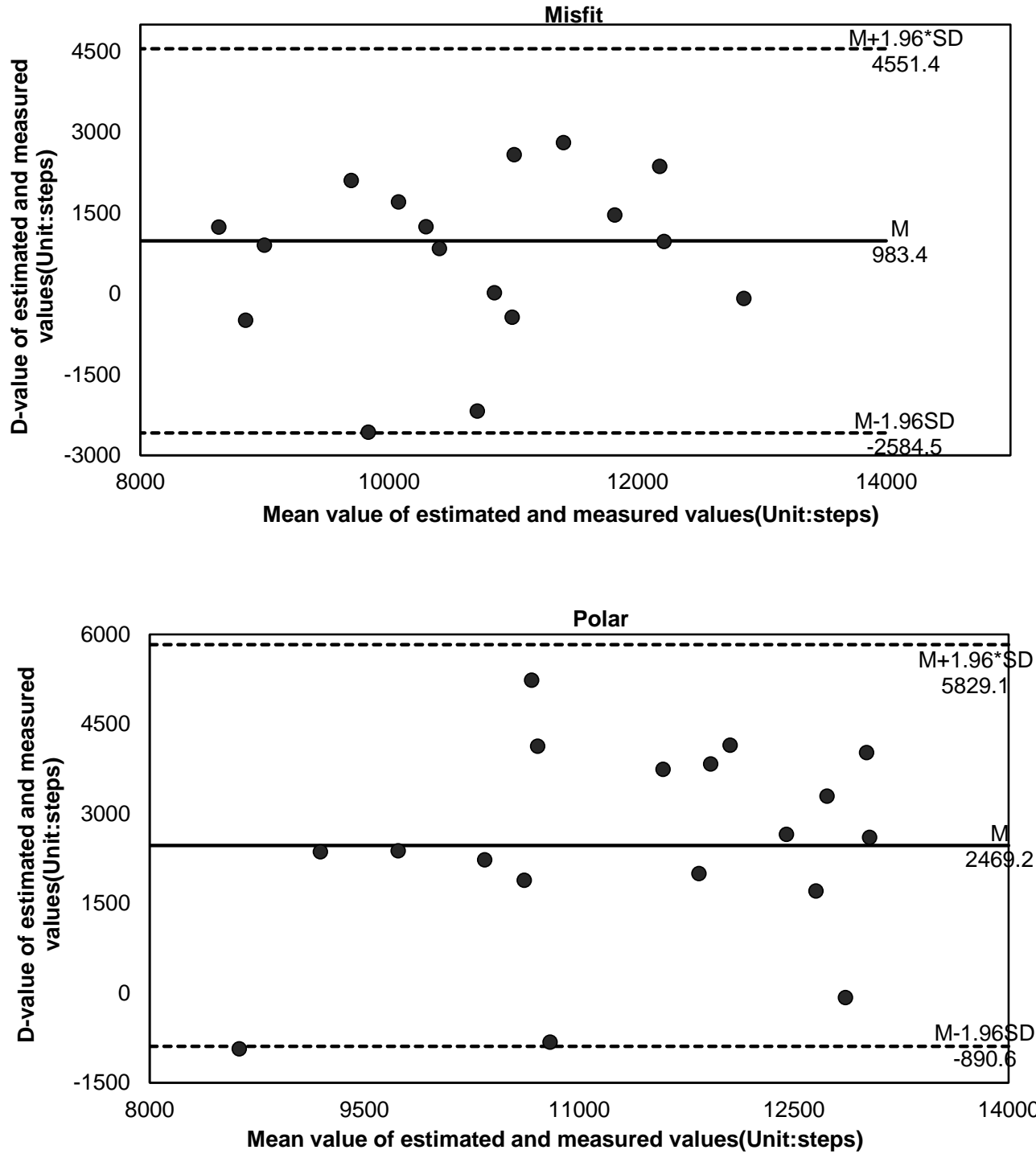

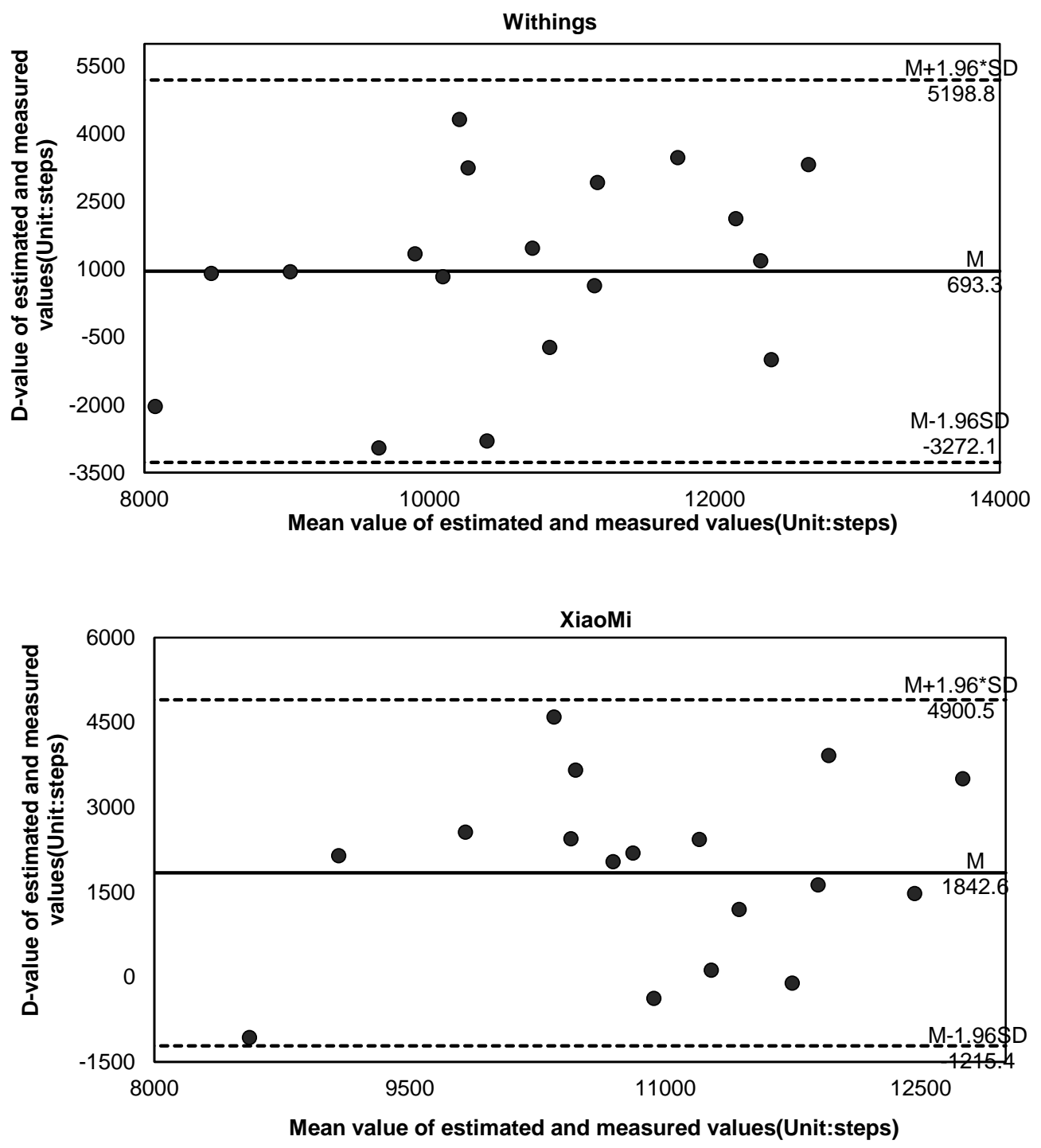

a 


\section{Energy expenditure:}
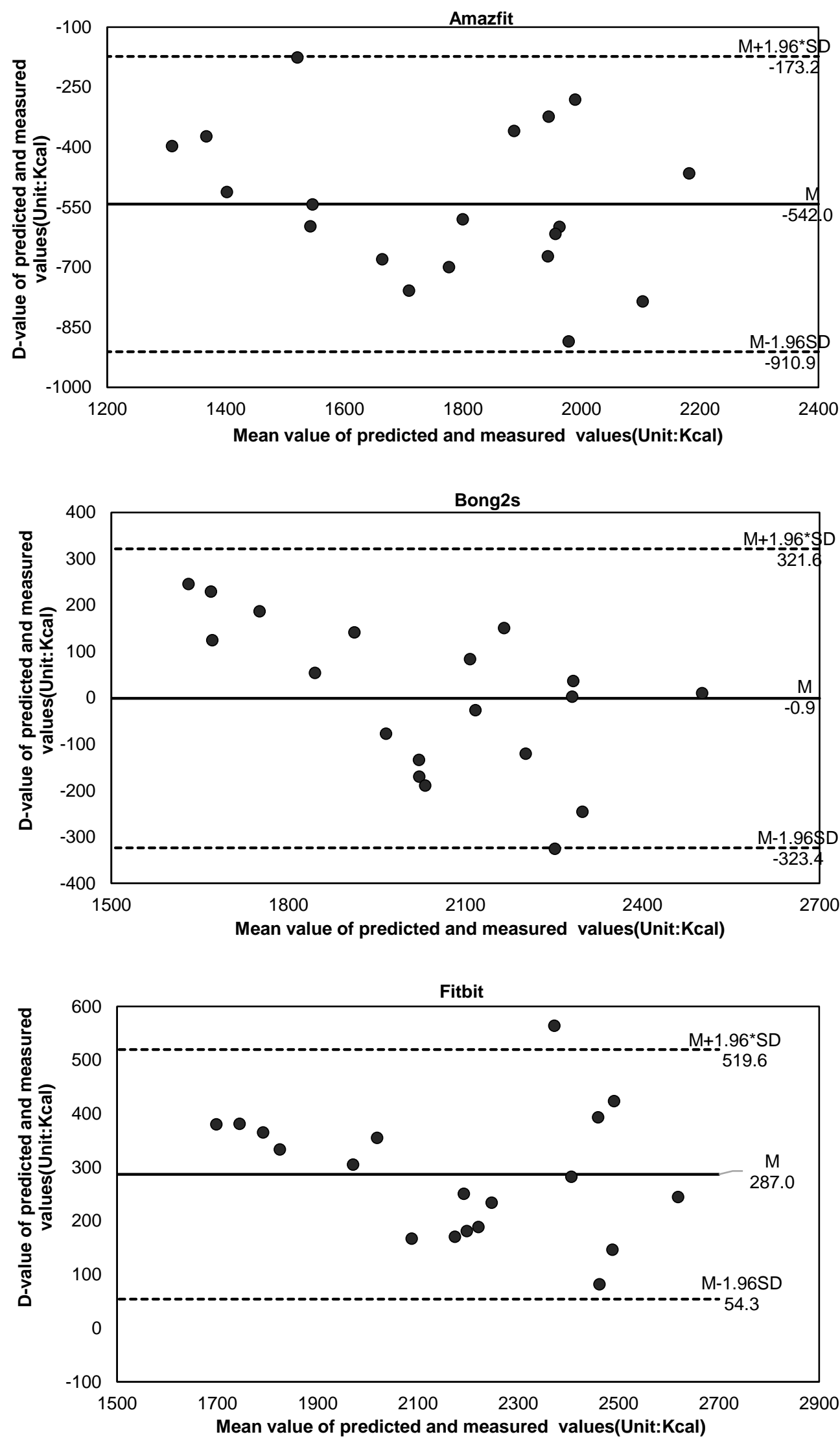

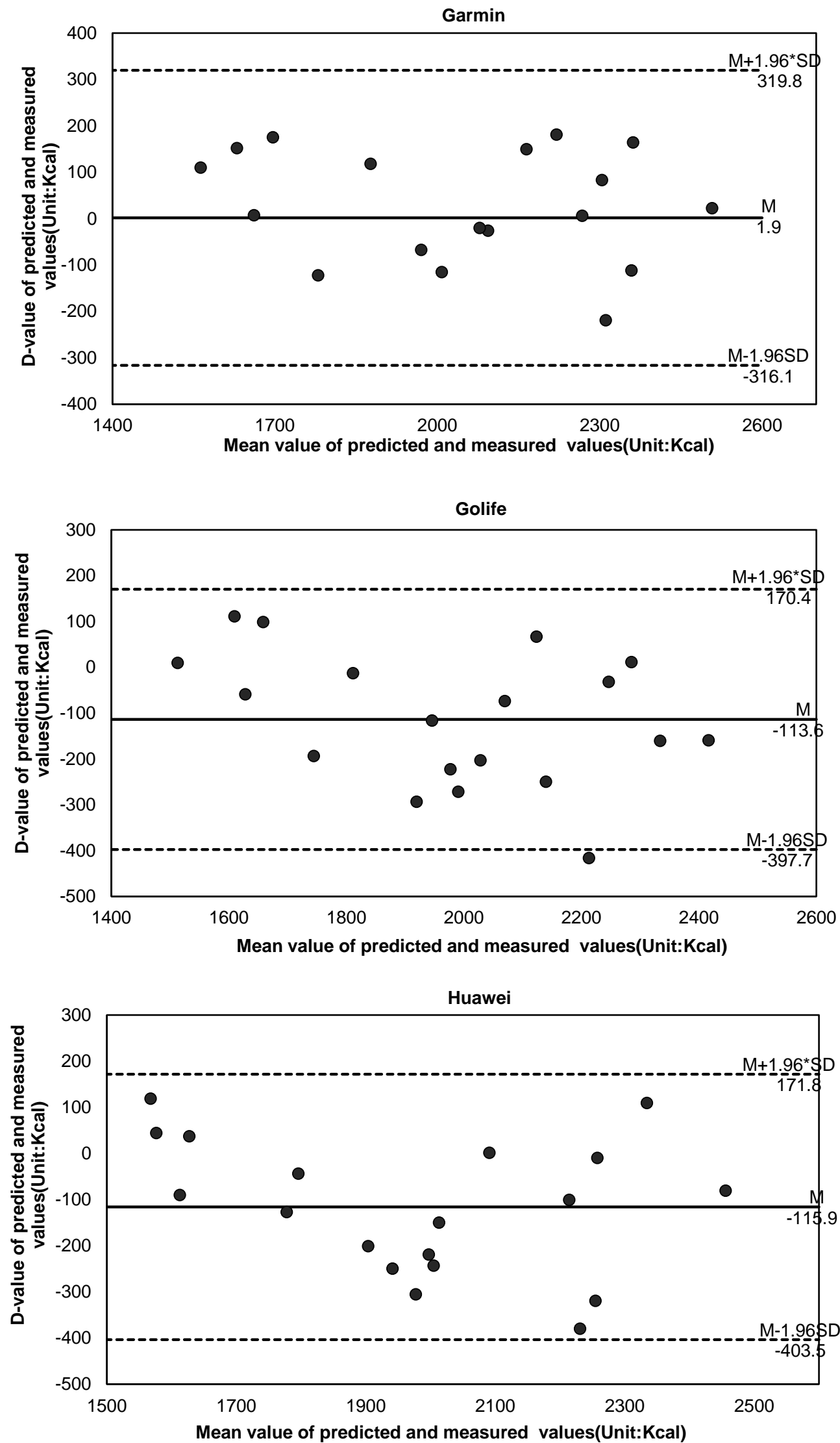

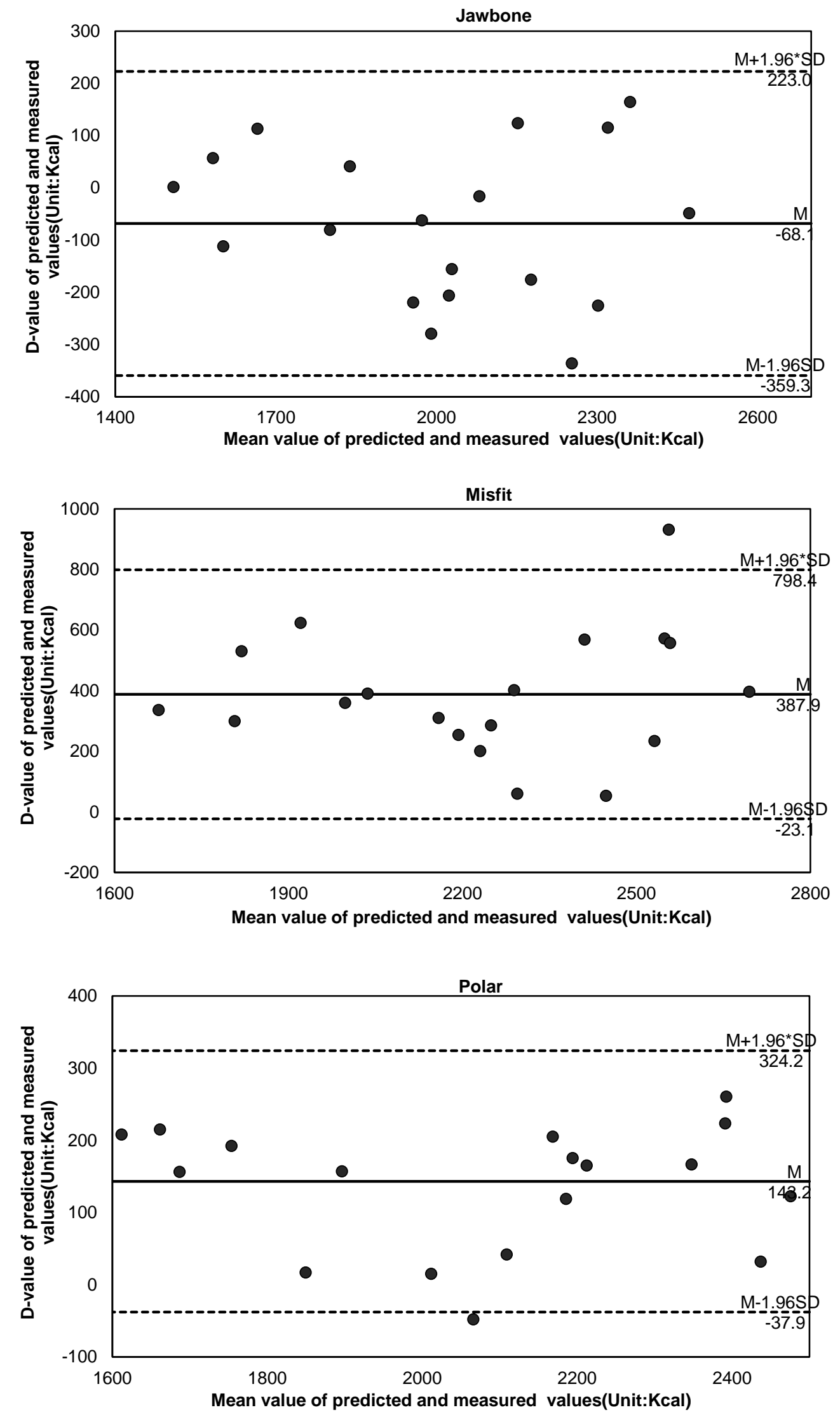

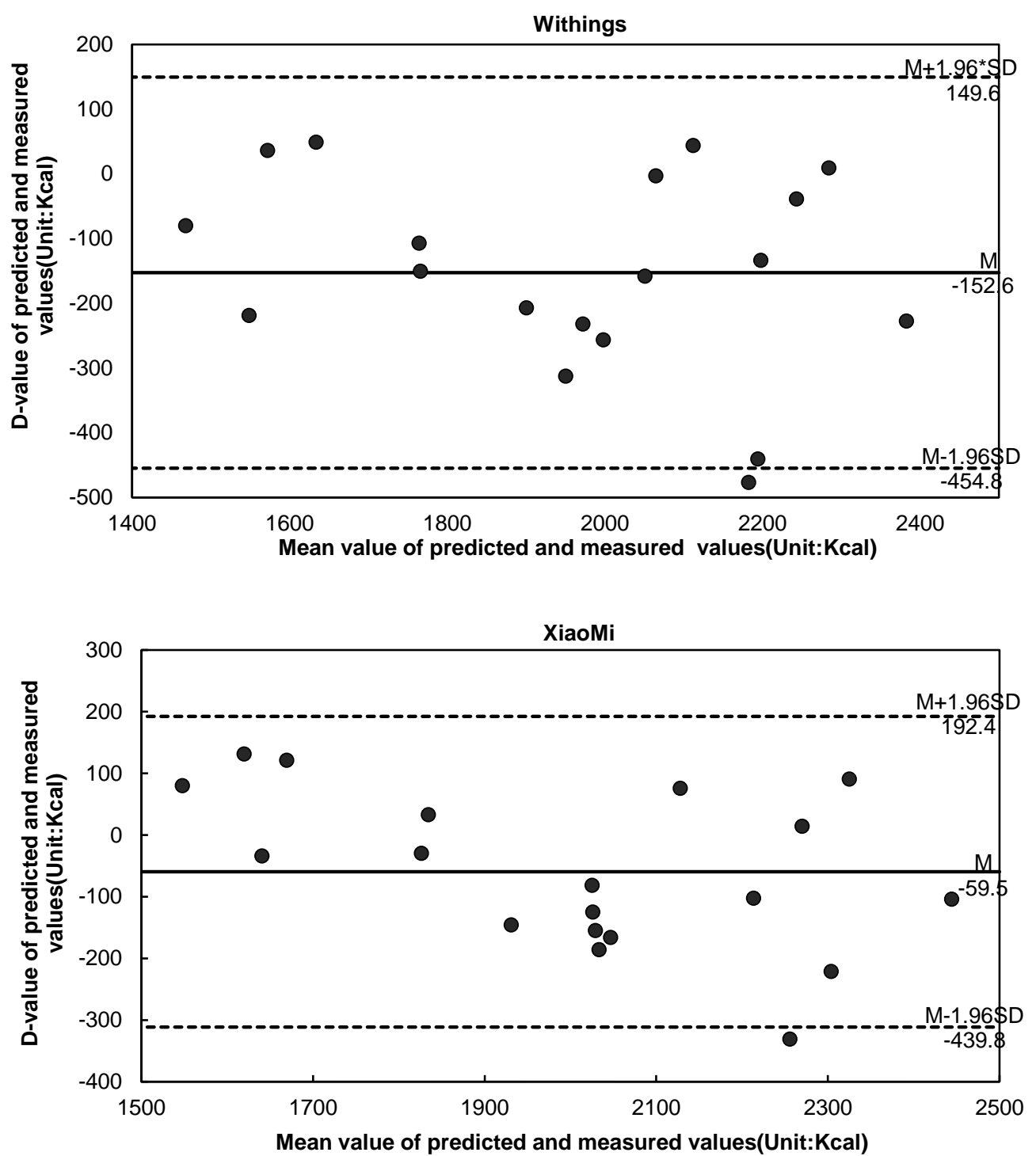

b

Figure S1 The Bland-Altman scatterplot of each wrist-wearable activity devices for steps and total energy expenditure. 